\title{
Commentary
}

\section{While waiting for COVID-19 vaccine rollout and/or treatment!}

\author{
Victor Wutor* \\ ${ }^{1}$ Department of Biotechnology, Microbiology and Public Health, AE Serve, Lethbridge, AB, Canada \\ ${ }^{2} \mathrm{ViVa}$ Atlantis Pharmacy, Accra. Ghana
}

Received: 09 January 2021

Revised: 19 January 2021

Accepted: 20 January 2021

\section{*Correspondence:}

Dr. Victor Wutor,

E-mail: vcwutor@gmail.com

Copyright: ( $)$ the author(s), publisher and licensee Medip Academy. This is an open-access article distributed under the terms of the Creative Commons Attribution Non-Commercial License, which permits unrestricted non-commercial use, distribution, and reproduction in any medium, provided the original work is properly cited.

\begin{abstract}
While expecting Covid-19 vaccine rollout and/or treatment, there are several things governments, healthcare professionals, scientists, and citizens could do to limit further spread and loss of lives. The world is making progress, but we cannot become complacent! Governments need to be honest and transparent with their citizens and listen to the experts. Scientists and healthcare professionals need to be willing to share information and experiences with their colleagues around the globe. It's time for some healthcare professionals like Pharmacists to step up and take other responsibilities. We are in this together!.
\end{abstract}

Keywords: Covid-19, Pharmacists, Vaccine

\section{INTRODUCTION}

Globally, efforts are focused on taking steps to contain the outbreak and forestall further spread. With confirmed COVID-19 cases worldwide nearly 90 million (and over 1.9 million deaths) and continuing to grow, scientists are pushing forward with efforts to develop vaccines and/or treatments to slow the pandemic and lessen the disease's damage. The general consensus amongst scientists and experts in the field of pandemics is that some of the earliest treatments will most likely be drugs that are already in use for treating other conditions or are have been tested on other viruses. Several companies are also busy working to develop vaccines that would be used as a preventive measure against the disease.

Researchers are testing 64 vaccines at different clinical trial stages on humans. Forty-three vaccines are at Phase 1 clinical trial stage, 20 at Phase 2, and another 20 at Phase 3. Three vaccines (by PfizerBioNTech, Moderna, and Oxford-AstraZeneca) are approved for full use, 7 have limited use/early use in some jurisdictions and one was abandoned after clinical trials. ${ }^{1}$ Until a master rollout plan is in place for Africa and other jurisdictions, the foremost effective strategy to stop illness is to avoid being exposed to the virus. It is known that the virus spreads mainly from person-to-person. In general, the more closely you interact with others, and the longer that interaction, the higher the probabilities of COVID-19 spread.

Drug development is typically described as a pipeline with compounds moving from early laboratory development to laboratory and animal testing to clinical trials in people (https://www.modernghana.com/news/1012484/clinicaltrialshero-or-villain.html). It can take a decade or more for a brand-new compound to travel from initial discovery to the marketplace. A very high percentage of compounds never make it that far. This is one reason why 
medications being targeted as potential treatments for COVID-19 are drugs that exist already.

Apart from antiviral drugs and vaccines, researchers are carefully studying other treatment options, some supported by interesting hypothesis:

- Ibuprofen clinical test: the thought is predicated on ibuprofen's anti-inflammatory qualities, which could help to ease breathing difficulties associated with the illness.

- Interferon-beta: this protein is produced by the body during viral infections.

- Apilimod: employed in treating autoimmune diseases and follicular lymphoma. The hypothesis is that apilimod can block cellular entry of the virus that causes COVID-19.

- Monoclonal antibodies: These drugs trigger our immune system to attack the virus.

- Convalescent plasma: this is plasma from people who have recovered from COVID-19 infection. The rationale is that their plasma contains antibodies that will attack this particular coronavirus.

- Immune modulators - It has been observed that when some people get infected with the virus, their system goes into overdrive, releasing large amounts of small proteins called cytokines, which are associated with the severity of the infection. The most popular drug used to combat cytokine storm is the inexpensive corticosteroid dexamethasone

- Stem cells: phase II/III clinical trials are currently ongoing for potential somatic cell treatment.

While the main targets are looking at the development of new treatments and/or vaccines for COVID-19, improvements in how Physicians take care of patients using the prevailing technology are also crucial. We need more testing and contact tracing, mandatory masks under all circumstances, hand sanitizers, more personal protective equipment and if necessary, a ban on nonessential travels. Hand sanitizers aren't a substitute for handwashing, but a necessary substitute when a chance for the latter isn't available. Neither are face shields a substitute for face masks. There is an absolute need for evidence-based but flexible standard treatment guidelines (STGs). Fortunately, most countries do have a robust STG for COVID-19.

The general public should be sensitized and educated on the potential need for volunteers for clinical trials. ${ }^{2}$ Also, COVID-19 recovered patients must be educated and sensitized to become convalescent plasma donors to help the severely and critically ill patients. Our researchers/healthcare professionals must keep and document all relevant data on the virus and make these available through publications for the advantage of their colleagues in other jurisdictions. Most healthcare professionals are doing an exquisite job with limited resources, and these cannot go unnoticed.
Governments must listen to the experts and not solely be thinking about the impact of COVID-19 on the economy! They must be proactive in educating and engaging antivaxxers and roll out educational programs against vaccine conspiracy propagation from the fear of autism development in developed countries to fear of intentional reproductive health decline in developing countries. Unfortunately, conspiracy theories spread faster than the virus! Governments must provide frequent and transparent communications to the general public, and embark on community engagements, so the public can maintain trust within the system to safely meet their essential needs. Such activities ensure that people will seek care when appropriate, and adhere to public health advice.

Governments must be proactive so their citizens aren't left behind when any treatment/vaccine becomes available. They ought also to plan appropriately on effective and efficient ways to roll out treatments/vaccines seamlessly once they become available. The COVID-19 pandemic is straining health systems worldwide. The increasing demand for health facilities, workers, and services is a threat to health systems. This situation could completely shut down some already weak and fragile systems. ${ }^{4}$

Lessons from previous outbreaks clearly showed that when health systems are overwhelmed, mortality from vaccine-preventable and other treatable conditions increase drastically. During the 2014-2015 Ebola outbreak, the increased number of deaths caused by measles, malaria, HIV/AIDS, and tuberculosis as a result of health system failures exceeded deaths from Ebola. ${ }^{3,4}$ "The best defense against any outbreak may be a strong health system. COVID-19 is revealing how fragile many of the world's health systems and services are, forcing countries to make difficult choices on the way to best meet the requirements of their people" stressed WHO Director-General Tedros Adhanom Ghebreyesus.

Countries should identify essential services that will be prioritized in their efforts to maintain continuity of service delivery and make strategic shifts to ensure that increasingly limited resources provide maximum benefit for the population. They also must accommodate absolute best standards in precautions, especially in hygiene practices, and the provision of adequate supplies including personal protective equipment. This requires robust planning and coordinated actions between governments, health facilities and healthcare professionals. $^{5}$

Some examples of essential services that cannot be sacrificed because of COVID-19 include routine vaccination; reproductive health services including care during pregnancy and childbirth; care of young infants and older adults; management of psychological and mental conditions, non-communicable diseases and infectious diseases like HIV, malaria, and TB; critical inpatient therapies; management of emergency health 
conditions; auxiliary services like basic diagnostic imaging, laboratory services, blood bank services, among others. ${ }^{3,4}$ It is expected that well-organized health systems are still able to provide equitable access to essential service delivery throughout an emergency, thus, limiting direct mortality and avoiding increased indirect mortality.

In some countries, Pharmacists are helping with vaccinations and giving injections. There may be no better time to utilize such readily available human resources in countries where these professionals aren't providing such services, e.g., Ghana. According to a 2016 report by the International Pharmaceutical Federation (FIP) on pharmacists' impact on vaccination, Pharmacybased vaccination is available in a minimum of 36 countries and territories (covering nearly $1.8 \mathrm{bn}$ people) and has been proposed or is undergoing development in a further 16. A recent study that explored some Saudi community's needs and preferences associated with community immunization services demonstrated the necessity for community pharmacy immunization services. $^{7}$ Pharmacists improve direct access to vaccinations and serve in many important roles within the vaccination process in the United States of America. ${ }^{8}$ According to a government report on the 2018-2019 flu vaccinations in Canada, Pharmacies were the main vaccination centers, accounting for $35 \%$ of all flu vaccinations. $^{9}$

Pharmacists are medicine experts, front-line healthcare providers, and an integral member of the healthcare delivery team in every country. Pharmacists are the most readily accessible health care providers and find themselves in a perfect position to provide immunization services. Patients can easily reach out to pharmacists for education, counseling, monitoring, and administration of the vaccines. Expanding their scope of practice as vaccinators will ultimately further their contributions to public health. ${ }^{6}$ Another area that requires massive attention and support is the impact of COVID-19 on the psychological state/mental health of the people, especially frontline healthcare workers. Psychological and mental health problems are common and this could be due to financial pressures, unexpected difficulties, unemployment, or stressful situations at home and work. We urgently need mental health services and resources (e.g., free helplines or text lines) across the length and breadth of nations or communities, especially for healthcare workers who are at the forefront in the fight against COVID-19.

Here are some tips to help reduce stress and promote wellbeing!

\section{Pause. Breathe. Reflect}

- Take some slow breaths: in through your nose, then slowly expire. Slow breathing is one of the many ways to lower stress because it signals to your brain to relax your body.
- Notice how you are feeling and what you're thinking, without judgment. Instead of responding or reacting to those thoughts or feelings, note them, and slowly allow them to go.

- Connect with others - reach out to people you trust can help. Maintain regular contact with people near you and be ready to voice out how you are feeling and share any concerns that you may have.

If you're a frontline health care provider, please put it in your mind that you simply aren't the sole savior of the COVID-19 world. You will lose some patients despite your best efforts, and you will also have saved some. After work, let your mind celebrate the recoveries! Keep to a healthy routine.

A few tips to keep you going!

- Get up and retire to bed at similar times daily.

- Maintain acceptable levels of private hygiene.

- $\quad$ Eat healthy meals at regular times.

- Exercise regularly. Just do 3-4 minutes of intense physical movement

- Apportion time for working and time for resting.

- Make time for doing the items you enjoy.

- Take regular breaks from on-screen activities.

- Don't use alcohol and medicines as how of handling fear, anxiety, boredom, and social isolation

- $\quad$ Be kind to yourself and others.

- On difficult days, don't expect too much of yourself.

- Accept that you'll be more productive on some days than others.

- Try to reduce the amount of time you spend to observing, reading, or listening to news that produces feelings of hysteria or distress.

- Seek the most recent information from trusted sources at specific times of the day.

- Helping others is also good for your general wellbeing.

- Reach out for help if need be, and don't hesitate to seek professional help.

Stay informed, be prepared, and follow public health advice!!!

Coronavirus may never go away!!!

Funding: No funding sources

Conflict of interest: None declared

Ethical approval: Not required

\section{REFERENCES}

1. World Health Organization. WHO-Coronavirus, 2020. Available at: https://www.who.int/health- 
topics/coronavirus\#tab=tab_1. Assessed Jan 09, 2021.

2. Wutor, Victor. Clinical Trials - Hero or Villain?, 2020. Available at https://www.modernghana.com/news/1012484/clini cal-trials-hero-or-villain.html Modernghana, Assessed June 28, 2020.

3. Elston JW, Cartwright C, Ndumbi P, Wright J. The health impact of the 2014-15 Ebola outbreak. Public health. 2017;143:60-70.

4. Parpia AS, Ndeffo-Mbah ML, Wenzel NS, Galvani AP. Effects of response to 2014-2015 Ebola outbreak on deaths from malaria, HIV/AIDS, and tuberculosis, West Africa. Emerg Infec Dis. 2016;22(3):433.

5. WHO guidelines to help countries maintain essential health services during the Covid-19 pandemic, 2020.

6. International Pharmaceutical Federation (FIP) - An overview of current pharmacy impact on immunization - 2016 Report, 2016. Available at: https://www.fip.org/files/fip/publications/FIP_report _on_Immunisation.pdf. Assessed June 28, 2020.
7. Al Aloola N, Alsaif R, Alhabib H, Alhossan A. Community needs and preferences for community pharmacy immunization services. Vaccine. 2020;38(32):5009-14.

8. Beal JL, Kadakia NN, Reed JB, Plake KS. Pharmacists' impact on older adults' access to vaccines in the United States. Vaccine. 2020;38(11):2456-65.

9. Vaccine uptake in Canadian Adults, 2019. Available at: https://www.canada.ca/en/publichealth/services/publications/healthy-living/20182019-influenza-flu-vaccine-coverage-surveyresults.html. Assessed June 28, 2020.

Cite this article as: Wutor $\mathrm{V}$. While waiting for COVID-19 vaccine rollout and/or treatment!. Int J Community Med Public Health 2021;8:845-8. 